University for Business and Technology in Kosovo

UBT Knowledge Center

UBT International Conference

2014 UBT International Conference

Nov 8th, 10:30 AM - 10:45 AM

\title{
Evaluation of the Behavior of Flat Slab Systems Subjected to Lateral Loads
}

\author{
Misin Misini \\ University of Prishtina, misin.misini@uni-pr.edu \\ Ylli Pocesta \\ University Skopje, yllipocesta@gmail.com \\ Zijadin Guri \\ University Skopje, guri.zijadin@gmail.com
}

Follow this and additional works at: https://knowledgecenter.ubt-uni.net/conference

Part of the Architecture Commons

\section{Recommended Citation}

Misini, Misin; Pocesta, Ylli; and Guri, Zijadin, "Evaluation of the Behavior of Flat Slab Systems Subjected to Lateral Loads" (2014). UBT International Conference. 14.

https://knowledgecenter.ubt-uni.net/conference/2014/all-events/14

This Event is brought to you for free and open access by the Publication and Journals at UBT Knowledge Center. It has been accepted for inclusion in UBT International Conference by an authorized administrator of UBT Knowledge Center. For more information, please contact knowledge.center@ubt-uni.net. 


\title{
Evaluation of the Behavior of Flat Slab Systems Subjected to Lateral Loads
}

\author{
Misin Misini ${ }^{1}$, Ylli Pocesta ${ }^{2}$, Zijadin Guri ${ }^{3}$ \\ ${ }^{1}$ Univeristy of Prishtina, Faculty of Civil Engineering and Architecture, \\ ${ }^{23}$ University, Faculty of Cilil Engineering in Skopje, \\ misin.misini@uni-pr.edu, yllipocesta@gmail.com,guri.zijadin@gmail.com
}

\begin{abstract}
In this paper behavior of flat slab structures under lateral loads, has been evaluated and analyzed. Flat slab structures show more flexibility and lateral displacement of this type of structures are considerable greater comparing to other systems. Nonlinear behavior in the regions near the slabcolumn connection and the change of stiffness in this region needs to be taken into account during the analysis. Slab-column connection characteristics needs to include the potential for punching failure which rise as a function of gravity shear ratio and the interstory drift ratio. Modeling of this type of structures based on effective slab width, which is based in flat slab frame, it describes in the best manner the behavior during lateral loads in sense that pushover and P-delta can be included to the analysis. The theoretical moment distribution from slab to column, and lateral drift in many studies has shown poor agreement with practical results. Ductile properties of the plastic hinges and their prediction of occurrence must be included in analytical model in order to represent the real behavior of this type of structures. Slab shear reinforcement over the columns will avoid the brittle punching shear failure and will provide a necessary strength and ductility to withstand lateral drift during seismic loads. Multi story buildings with flat slabs needs to include shear walls or other stiffer systems to provide good resistance and would limit the inter-story drifts.
\end{abstract}

Keywords: Flat slab, interstory drift, effective slab width, plastic hinges, lateral loads

\section{Introduction}

Flat slab system, even it is very effective in resisting gravity loads, in itself it is quite flexible and it can suffer high horizontal displacement during seismic actions. Its sensitivity during seismic damages it is well documented in many research studies.

In the regions with high seismic activity, flat slab system is designed in that way that space frame with slab-column resist the gravity loads and the shear walls to provide all the resistance against lateral loads (Wey and Durrani 1992; Robertson and Durrani 1992; Moehle and Diebold 1985). Furthermore, the subsystem for gravity load must be able to accept the same deformations which occur in the lateral load system without losing bearing capacity. For this, in reality both systems act together. Because that design seismic loads as it is stated by the various codes are smaller comparing to those which occur during strong earthquake, considerable nonlinear behavior will occur.

Adapting the flat slab system in construction of reinforced concrete structures it became practice in many European countries which belongs in high seismic regions. These type of structures are common for residential and office/administration buildings. Even national codes include the rules for design of these structures, Eurocode 8 doesn't cover this point. Behavior of this type of structural system shows significant disadvantages, which are nondisipative characteristics of their seismic behavior. Also, flat slab structures are much flexible comparing to traditional structures frame-wall or frame structures, this makes this system more vulnerable during seismic actions. For this reason, seismic behavior characteristics of the flat slab structures have surplus demands which have to be taken into account during conceptualization and design of this structures in seismic regions, one of them is combination with other seismic systems. 
Primary importance has the evaluation of the effective slab width and needs to be taken into account during analyzing flat slab structures. Results from the recent tests have shown that participation of the slab in the behavior of the structure under the lateral loads is very small.

\section{Modeling of the slab-column connections in frames}

Modeling of slab-column frames, commonly used as gravity systems in tall core wall buildings, involves assigning appropriate values for stiffness and strength, and includes considerations of punching failure. Current information on modeling of slab-column frames can be found in ASCE/SEI 41-06 Supplement No. 1, and in Elwood et al. (2007).

\subsection{Quantification of Properties for Slab-Column Frames}

The effective flexural stiffness of the slab can be modeled using slab effective beam-width models from sources such as Allen and Darvall (1977). In this model, the centerline panel-to-panel transverse width measured perpendicular to the direction of loading under consideration, is reduced by the normalized effective stiffness, as given in Equation 1.

$$
\mathrm{E}_{\mathrm{c}} \mathrm{I}_{\mathrm{effective}}=\mathrm{E}_{\mathrm{c}} \beta\left[\alpha \mathrm{l}_{2} \mathrm{~h}^{3} / 12\right] .
$$

where $\mathrm{h}$ is the total slab thickness, and the other parameters are described below.

The elastic effective width is represented by $\alpha l_{2}$, which depends on $\mathrm{c}_{1}$, the column dimension parallel to the slab, and $l_{1}$, the center-to-center span length in the direction under consideration. Hwang and Moehle (2000) recommend the following values to determine the elastic slab effective width:

$$
\alpha \mathrm{l}_{2}=2 \mathrm{c}_{2}+11 / 3
$$

for interior frames, including the exterior connections, and:

$$
\alpha l_{2}=2 c_{2}+11 / 3
$$

for exterior frames loaded parallel to the edge.

The effective width given by Equation 1 is applicable for slab-column frame models in which the slab-beam is modeled as rigid over the width of the column (i.e., the joint region). Typical values of $\alpha$ for interior frames vary from $1 / 2$ to $3 / 4$ for reinforced concrete structures, and $1 / 2$ to $2 / 3$ for posttensioned structures. Values for exterior frames transferring load parallel to the edge are about half of those for interior connections.

A further stiffness reduction due to concrete cracking is represented by $\beta$. Stiffness reduction due to cracking depends on a number of factors including construction, service loads and earthquake loads, as well as the degree of post-tensioning. Typical values for $\beta$ vary from $1 / 3$ to $1 / 2$ for reinforced concrete construction (Allen and Darvall, 1977; Vanderbilt and Corley, 1983; Grossman, 1997; FEMA, 1997; Hwang and Moehle, 2000; Kang and Wallace, 2005).

Figure 1 shows the normalized effective stiffness, $\alpha \beta$, for interior connections calculated using Equations 1 through 3 over a range of span ratios, $l_{2} / l_{1}$. Effective stiffness values for exterior connections can be estimated as half of the values shown in the figure. 


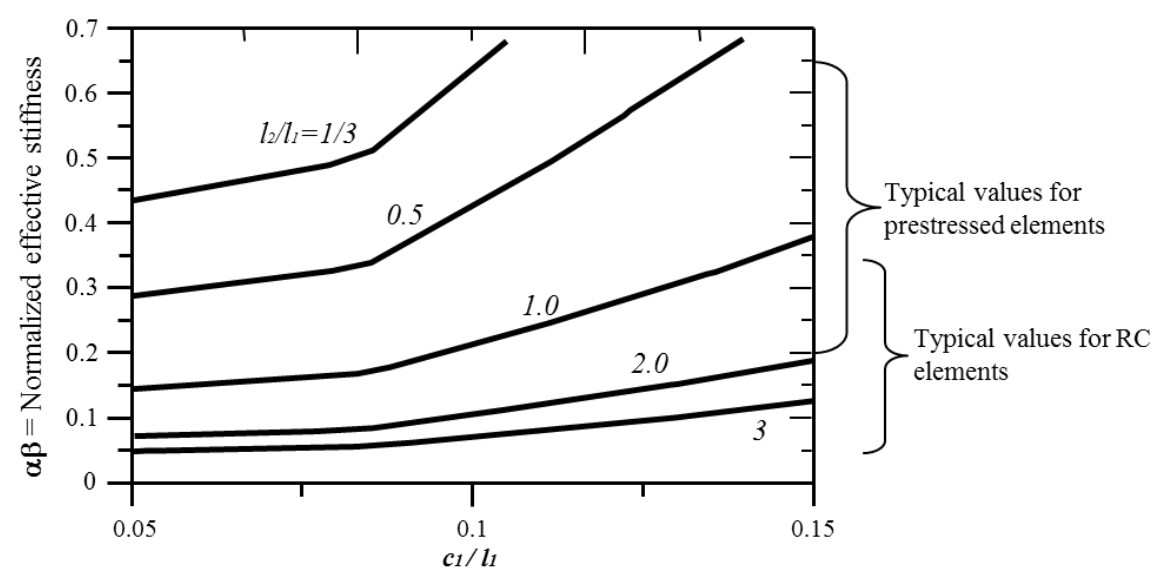

Fig. 1. Normalized effective stiffness factors for interior slab-column frames based on Equations 1 through 3.

Connections in which continuity reinforcement is provided are classified as deformation-controlled, and nonlinear behavior, both before and after punching, should be incorporated in the structural model. In a slab-column frame the failure occurs around the column, and this can lead to complications in modeling nonlinear behavior. One way to model this connection is through the inclusion of a zero-length torsional member that connects the column to adjacent slab-beams, as shown in Figure2.

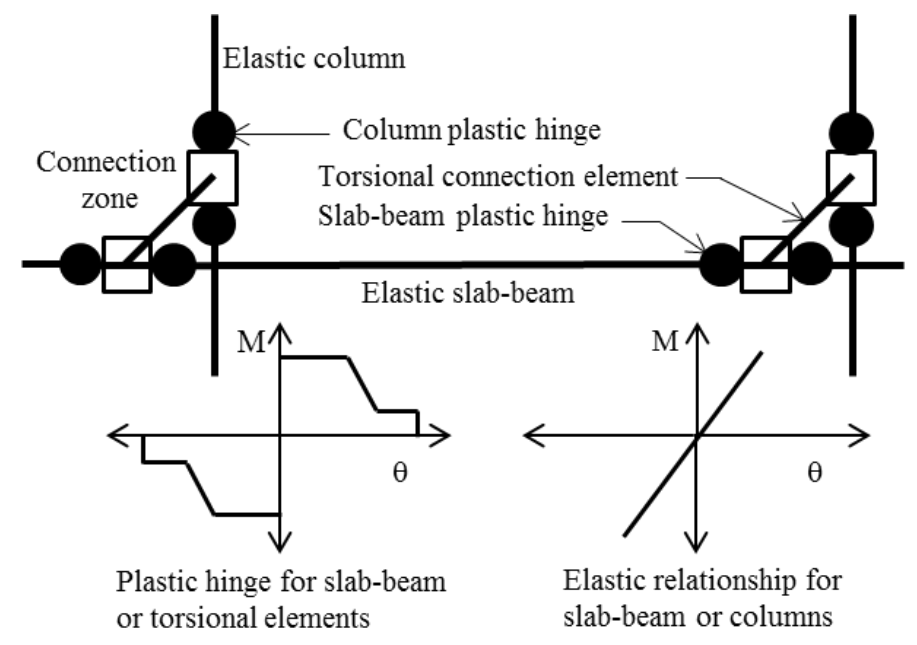

Fig. 2. Model of slab-column connection.

In this model, the column and slab-beam are modeled with concentrated hinges at each end representing the flexural strengths of the members. The torsion member is rigid until the connection strength is reached, after which nonlinear rotation is represented. An advantage of this model is that it enables the unbalanced moment, $\mathrm{M}_{\mathrm{con}}$, transferred from the slab to the column, as illustrated in Figure 3, to be tracked directly during the analysis. 


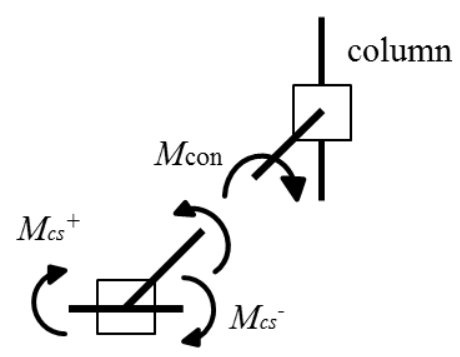

Fig. 3. Unbalanced moment transferred between the slab and column in a torsional connection element.

The strength of the torsional connection element is given by:

$$
\mathrm{M}_{\mathrm{n}, \mathrm{con}}=\min \left[\mathrm{M}_{\mathrm{f}} / \gamma_{\mathrm{f}} ; \mathrm{M}_{\mathrm{v}} / \gamma_{\mathrm{v}}\right] .
$$

where $\mathrm{M}_{\mathrm{f}} / \gamma_{\mathrm{f}}$ is the moment transferred in flexure, divided by the fraction of unbalanced moment transferred in flexure, and $\mathrm{M}_{v} / \gamma_{v}$ is the moment transferred by eccentric shear, divided by the fraction of unbalanced moment transferred in eccentric shear.

\subsection{Slab-column connection characteristics}

Modeling the behavior of slab-column frames need to address the potential for punching failure at slabcolumn connections, which may occur either prior to or after yielding of slab flexural reinforcement. For either case, punching failures of reinforced concrete interior connections have been shown to be primarily a function of the gravity shear ratio on the slab-column critical section and the interstory drift ratio imposed on the connection (Figure 4) as reported by Pan and Moehle 1996. Additional factors which impact the modeling of the slab-column behavior include the connection type interior, exterior, corner, as well as the type of floor system i.e., if posttensioning is used and whether shear reinforcement is provided. Slab-column connection models must address these issues, as well as the potential for yielding in flexure due to unbalanced moment transferred from the slab to the column within the slab flexural transfer width and the potential for punching failures both prior to and after yielding of slab flexural reinforcement.

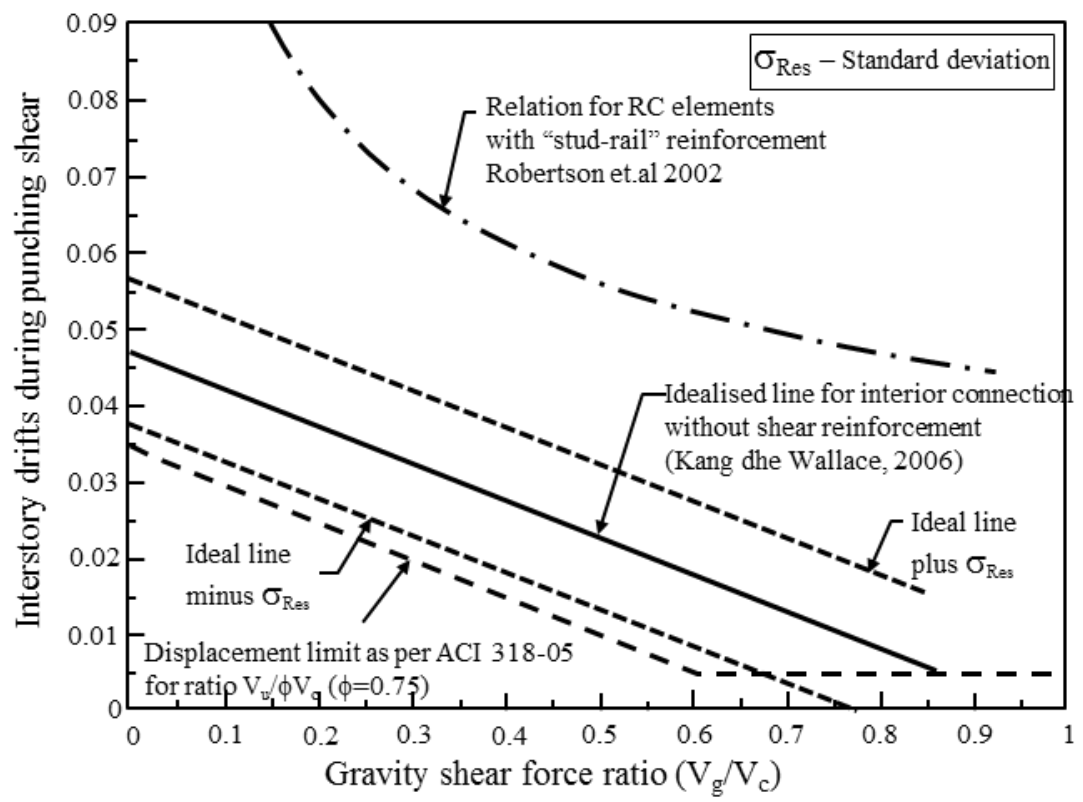

Fig. 4. Unbalanced moment transferred between the slab and columnin a torsional connection element. 
In different researches has been adopted the approach that column deformation do not contribute to much in the floor relative drifts in the structures with slab-column frames (the column is practically rigid), and therefore the sum of elastic and plastic rotations of slab are approximately equal to the relative drifts of the floors.

For slab-column connections, the limit state is determined using boundary conditions or certain node rotation of the slab-column connection or relative drifts of floors in combination with the ratio of transverse forces from gravitational loads of the joint (Pan and Moehle 1989; Megally and Ghali 1994, Robertson et al.2002; Kang and Wallace 2006).

\subsection{Application to Core Wall Systems}

Incorporation of core-wall system gives the opportunity to assess the potential impact of the gravity framing on response quantities of interest as are storey drifts, column axial load and the potential for slab-column punching failure.

The floor plan and simplified model of the combined slab-column frame and core wall system are shown in Figure 5. A simplified model is used to reduce computer run time. Four equivalent columns are used to represent the behavior of the gravity columns. Coupling between the core wall and the gravity columns is modeled using an equivalent slab beam, with properties determined using the effective beam width model.

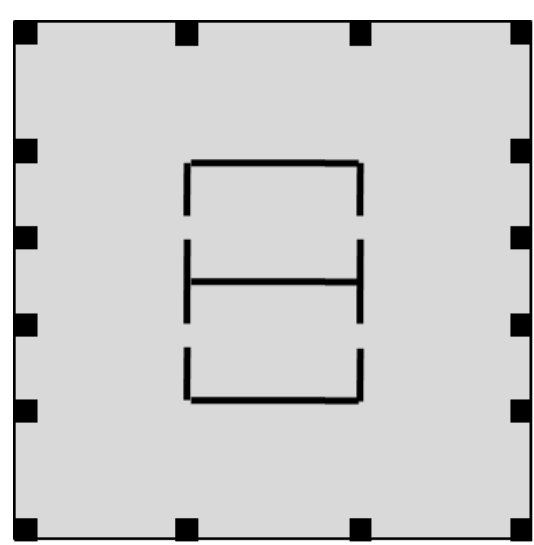

(a) Foor plan

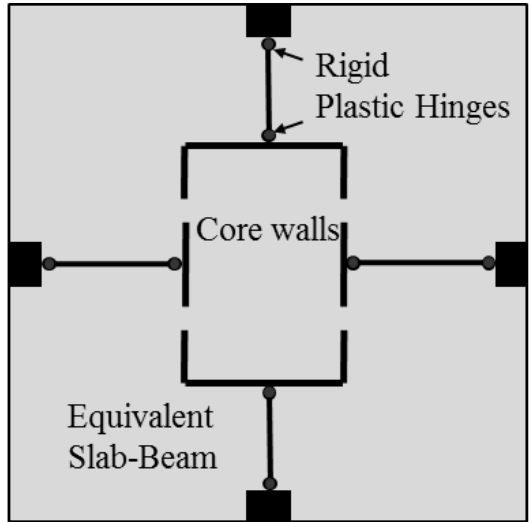

(b) Simplified model

Fig. 5. Floor plan and simplified model of the combined slab-column frame and core wall system.

The effective width for beams as it is shown in Figure 6, for beam B1 was determined by the ratios of $\mathrm{c}_{1} / \mathrm{l}_{1}$ and $\mathrm{c}_{2} / \mathrm{l}_{2}$, and the effective width of $\mathrm{B} 2$ was set equal to $\mathrm{l}_{2}$, given that the core wall spans the entire width of the beam. The two beams (B1 and B2) meet at a nodal point located at the center of the span, based on the approach recommended by Hwang and Moehle (2000). Effective EI values determined for the slab were multiplied by the $\beta$-factor to account for cracking. Yield moments in positive and negative bending for the slab-beams were determined based on fully anchored slab flexural reinforcement within the effective beam widths. 


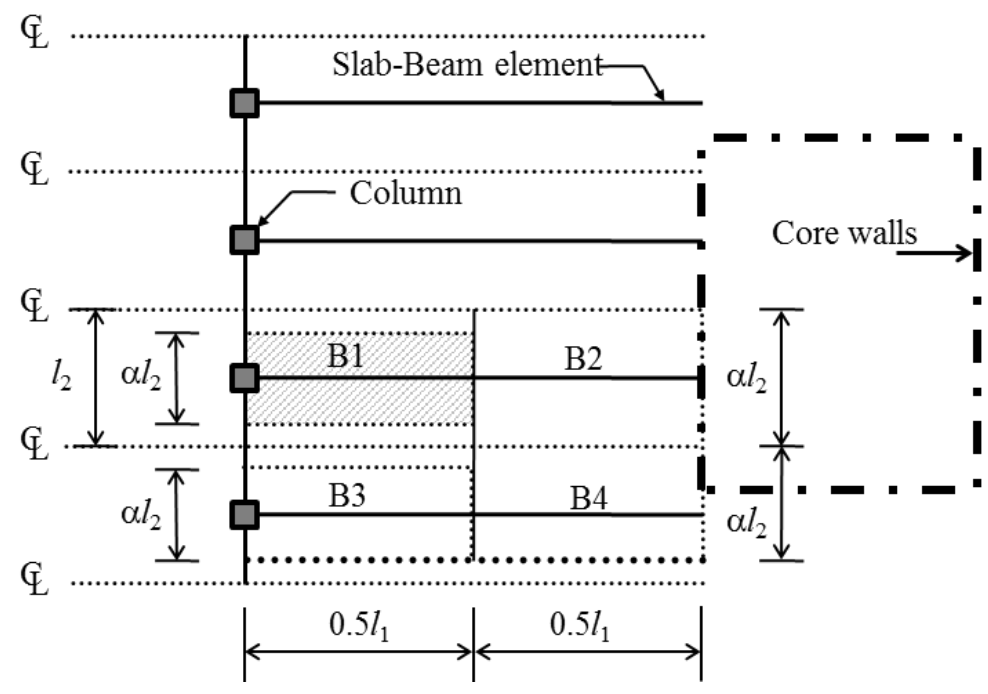

Fig. 6. Application of effective width model to core wall.

To further reduce computer run time, an additional simplification can be made. Plastic hinges may not be included at the ends of the equivalent slab-beams. Yielding in the slab would be expected to reduce the interaction between the slab-column frame and the core wall elements. As such, results represent an upper-bound measure of the effects of the gravity frame on response quantities of interest.

Use of the effective slab width model is recommended to model coupling between the core wall and the slab-column frame.

\section{Seismic Design Considerations for Slab-Column Connections}

Concrete flat slabs, supported directly on columns without beams or column capitals, are vulnerable to brittle punching shear failure due to the transfer of shear forces combined with moments between the slab and the columns. In the following is presented design of the slab shear reinforcement, to be provided in the vicinity of the columns; shear reinforcement to provide the strength and the ductility necessary to permit the slab-column connections to withstand, without punching, the deformations associated with the lateral drift in severe earthquakes.

Multistory buildings with flat slabs need to include shear walls or other systems to obtain a necessary resistance against horizontal loads which may limit the ratio of the horizontal drift of the floors, $\mathrm{DR}_{\mathrm{u}}$, in not bigger than 0.025 , where $\mathrm{DR}_{\mathrm{u}}$ is the interstorey drift, including the plastic deformations of the two consequent storeys. Some researches has shown that with right usage of the transverse reinforcement, it can be avoided punching shear failure of the column during big earthquakes.

Megally and Ghali recommend the design steps given below, which ensure that slabs endure the inelastic interstorey drift without punching shear failure, these design recommendations are being considered for adoption also by American Codes, ACI 421.

- Step 1: Determine the maximum elastic interstorey drift $\Delta_{\mathrm{e}}$, by:

$$
\Delta_{\mathrm{e}}=\mathrm{DR}_{\mathrm{u}} 1_{\mathrm{c}} /\left(\mathrm{C}_{\mathrm{d}} / \mathrm{l}_{\mathrm{E}}\right) .
$$

where $1_{c}$ is the storey height, $C_{d}$ and $l_{E}$ are dimensionless factors, specified by IBC-2003, representing respectively the inherent inelastic deformability of the lateral-force resisting system and the occupancy importance of the structure. 
- Step 2: Calculate the shear force and the unbalanced moment due to factored gravity load on the equivalent plane frame shown in Figure8. Determine the shear force and the unbalanced moment due to imposed displacements $\Delta_{\mathrm{e}}$ at the top ends of the columns of the frame in Figure 9. The moments of inertia of the frame members, indicated in Figure 10 are in accordance with ACI 318-05; the columns in each frame are assumed to be attached to the slab by torsional members running in direction perpendicular to the plane of frame. This assumption is implied by the use of an effective moment of inertia, $I_{e c}$ for the columns instead of their gross moment of inertia: $I_{c}=c_{y} c_{x}{ }^{3} / 12$ :

$$
\mathrm{I}_{\mathrm{ec}}=\mathrm{K}_{\mathrm{t}} \mathrm{I}_{\mathrm{c}} /\left(\mathrm{K}_{\mathrm{t}}+\Sigma \mathrm{K}_{\mathrm{c}}\right) .
$$

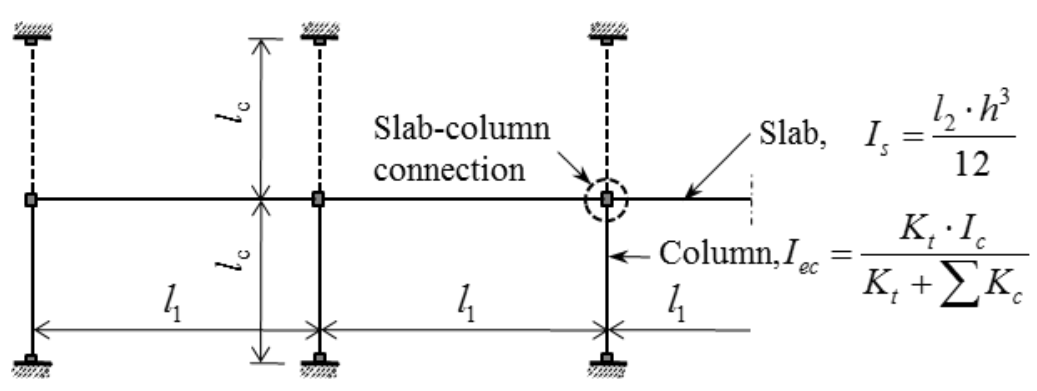

Fig. 8. Equivalent frame for gravitational load analysis.

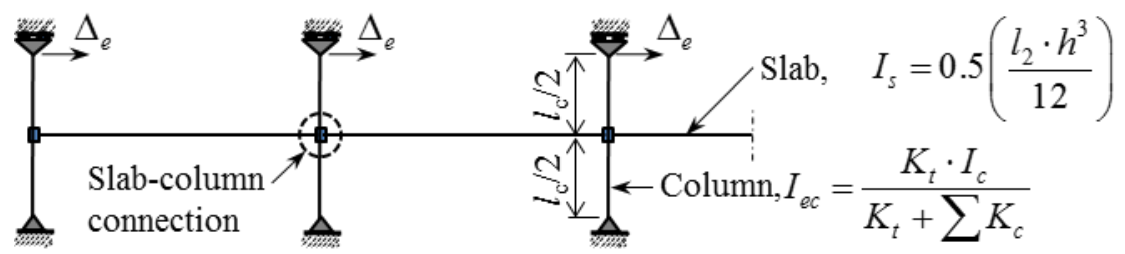

Fig. 9. Equivalent frame for lateral load analysis.

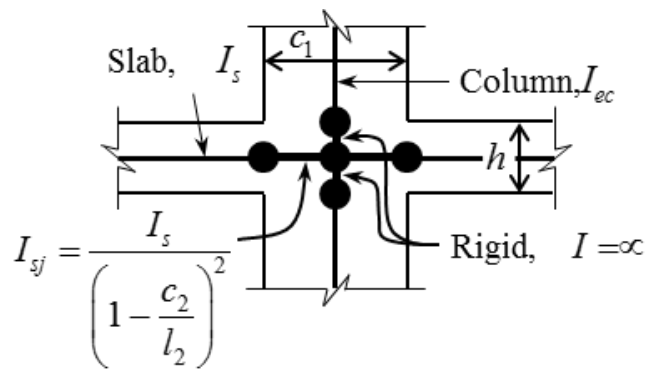

Fig. 10. Slab column connection in the equivalent frame.

where $\mathrm{K}_{\mathrm{t}}$ is twisting stiffness of the torsional member (moment per unit rotation) given by ACI 31805 equation:

$$
\mathrm{K}_{\mathrm{t}}=\Sigma\left(\left(3 \mathrm{E}_{\mathrm{c}}\left(\mathrm{c}_{\mathrm{x}}-0.63 \mathrm{~h}\right) \mathrm{h}^{3}\right) /\left(\mathrm{I}_{\mathrm{y}}\left[1-\left(\mathrm{c}_{\mathrm{y}} / \mathrm{I}_{\mathrm{y}}\right)\right]\right)\right)
$$

The summation is for the one or the two torsion members attached to the slab-column connection; $\Sigma \mathrm{K}_{\mathrm{c}}$ is the sum of the end rotational stiffness of the columns above and below the connection.

Determine the factored shear force $V_{u}$ and the unbalanced moment $M_{u}$ for the earthquake effect, resulting from the analysis of the frame in Figure 8b, combined with gravity load where D, L and $\mathrm{S}$ are dead, live and snow loads, respectively. 
The unbalanced moment that should be accounted for in punching shear design need not exceed:

$$
\mathrm{M}_{\text {upper,limit }}=\mathrm{M}_{\mathrm{pr}} / \alpha_{\mathrm{m}} \text {. }
$$

where $\mathrm{M}_{\mathrm{pr}}$ is the sum of the probable flexural strengths of opposite critical section sides of width $\mathrm{c}_{\mathrm{y}}+$ $\mathrm{d} ; \mathrm{M}_{\mathrm{pr}}$ should be determined using a tensile stress $1.25 \mathrm{f}_{\mathrm{y}}$, and $\alpha_{\mathrm{m}}$ is an empirical coefficient that is expressed for interior column-slab connections as:

$$
\alpha_{\mathrm{m}}=0.85-\gamma_{v}-\left(\beta_{\mathrm{r}} / 20\right) .
$$

where $\beta_{\mathrm{r}}$ is the ratio $\left(\mathrm{I}_{\mathrm{y}} / \mathrm{I}_{\mathrm{x}}\right)$ or $\left(\mathrm{I}_{\mathrm{x}} / \mathrm{I}_{\mathrm{y}}\right)$ for transferred moment about the $\mathrm{x}$ or $\mathrm{y}$ axis, respectively. Equation 9 governs the design only in the exceptional case of very low flexural reinforcement passing through the width $\left(c_{y}+d\right)$. In this case, the slab-column connection will undergo the inelastic drift ratio, $D_{u}$ with yielding of the flexural reinforcement in the vicinity of the column, without the demand for the full shear strength or the risk of punching shear failure.

- Step 3: Calculate the maximum shear stress $\mathrm{V}_{\mathrm{u}}$ at the critical section at $\mathrm{d} / 2$ from the column face and verify that it does not exceed:

$$
v_{\max }=\left\{\begin{array}{l}
5 \phi \sqrt{f_{c}^{\prime}} / 6, \text { when } V_{u} /\left(\phi \mathrm{V}_{\mathrm{c}}\right) \leq 1.0 \\
2 \phi \sqrt{f_{c}^{\prime}} / 3, \text { when } V_{u} /\left(\phi \mathrm{V}_{\mathrm{c}}\right)>1.0
\end{array} .\right.
$$

Otherwise, the structural members should be changed to reduce $\mathrm{V}_{\mathrm{u}}$ (e.g. by enlarging the column dimensions, or reducing $D_{\mathrm{u}}$ by stiffening the lateral force resisting system). If $V_{u}$ at $d / 2$ from the column face is greater or less than the factored strength $\varphi \mathrm{V}_{\mathrm{c}}$, go to step 4 or 5 , respectively.

- Step 4: Provide shear reinforcement such that $\varphi\left(v_{\mathrm{cs}}+v_{\mathrm{s}}\right) \geq v_{\mathrm{u}}$, with $v_{\mathrm{cs}}, v_{\mathrm{s}}$ and the extent of shear reinforcements satisfying the conditions in the steps above. Terminate the design by verifying that the provided shear reinforcement exceeds the minimum, given by:

$$
v_{s} \geq(1 / 4) \sqrt{f_{c}^{\prime}},[M P a] ; l_{\text {sh-zone }}>3.5 d .
$$

where $1_{\mathrm{sh} \text {-zone }}$ is the distance from the column face to the outermost peripheral line of shear reinforcement.

- Step 5: If $v_{\mathrm{u}}<\varphi v_{\mathrm{c}}$ (with $v_{\mathrm{c}}$ calculated by Equation 11), should be provided when the point $\left\{V_{u} /\left(\varphi V_{c}\right) D R_{u}\right\}$ lies in the shaded zone $A$ in Figure 11 ; where $V_{c}=v_{c} b_{0} d$; otherwise, no shear reinforcement is recommended.

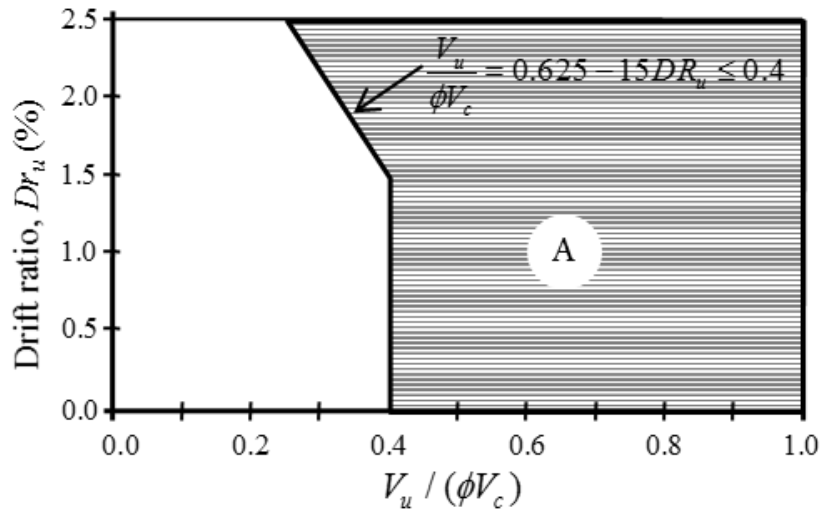

Fig. 11. Requirement criteria of shear reinforcement. 


\section{Design Example}

Design procedure and modeling techniques of flat slab structures described in this paper are illustrated by en example using SAP 2000 software. Reinforced concrete structure with six floors and four bays $4 \times 6 \mathrm{~m}$ in each direction. Storey height is set to $3 \mathrm{~m}$. Column dimensions are $50 \times 50 \mathrm{~cm}$ and the slab is set to $20 \mathrm{~cm}$. Concrete class used in the model is $\mathrm{C} 25 / 30$ and the steel S500. This example is based in Eurocode 8 taking into account the following parameters: design ground acceleration ag=0.22g, soil category $\mathrm{C}$, behavior factor $\mathrm{q}=1.5$ and the importance factor $\gamma_{\mathrm{I}}=1.0$.

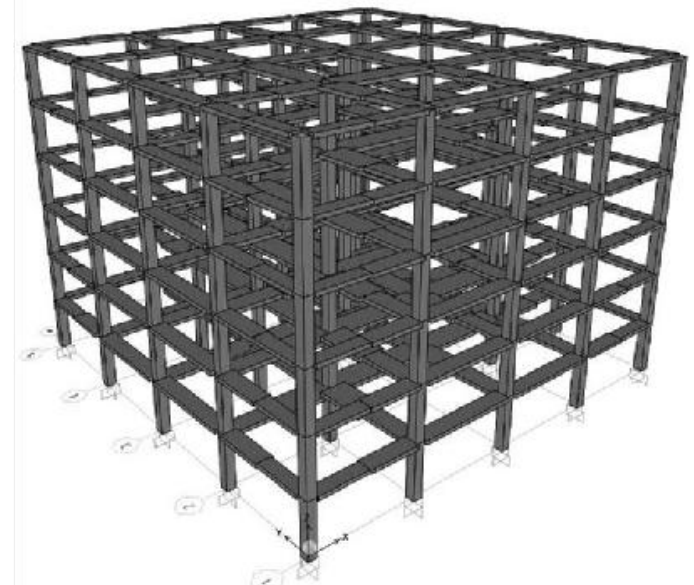

Fig. 12. Mathematical model of the structure.

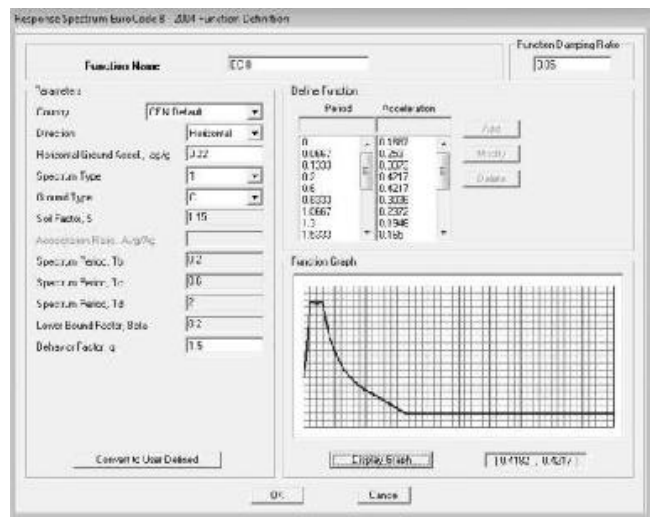

Fig. 13. Design spectrum and other relevant parameters.

From the analysis results we found that the fundamental period of the structure is $T_{1}=1.48 \mathrm{sec}$.

a) Interstorey drift

Maximum interstorey drift is taken at first floor: $\mathrm{dr}(\mathrm{I})=4.65 \mathrm{~cm}$, the value of $v$ factor according to Eurocode 8 is 0.5 for importance factor II.

The interstorey drift the following conditions must be satisfied:

- for buildings having non-structural elements of brittle materials attached to the structure: $\mathrm{dr} \leq 0.005 \mathrm{~h} / \mathrm{v}=0.005 \times 300 / 0.5=3 \mathrm{~cm}$

- for buildings having ductile non-structural elements: $\mathrm{dr} \leq 0.0075 \mathrm{~h} / \mathrm{v}=0.0075 \times 300 / 0.5=4.5 \mathrm{~cm}$

From the above results we can conclude that the interstorey drifts do not satisfy the conditions.

b) P- $\Delta$ effect 
Table 1. Intestorey drift calculation.

\begin{tabular}{lrrrrrrl}
\hline Level & $\mathrm{m}[\mathrm{T}]$ & \multicolumn{1}{c}{$\mathrm{Ni}[\mathrm{kN}]$} & Vxi $[\mathrm{kN}]$ & vxi $[\mathrm{cm}]$ & $\Delta$ vi $[\mathrm{cm}]$ & $\Delta$ di $[\mathrm{cm}]$ & $\theta \mathrm{i}$ \\
\hline Level 6 & 6631.4 & 65054.03 & 2342 & 14.00 & 1.60 & 2.40 & 0.222 \\
Level 5 & 6870.4 & 132452.66 & 5489 & 12.40 & 2.30 & 3.45 & 0.278 \\
Level 4 & 6870.4 & 132452.66 & 5972 & 10.10 & 2.70 & 4.05 & 0.299 \\
Level 3 & 6870.4 & 199851.28 & 10058 & 7.40 & 3.10 & 4.65 & 0.308 \\
Level 2 & 6870.4 & 267249.91 & 14840 & 4.30 & 2.84 & 4.26 & 0.256 \\
Level 1 & 6870.4 & 334648.53 & 20124 & 1.46 & 1.46 & 2.19 & 0.121 \\
\hline
\end{tabular}

In Eurocode 8 the value of $\theta$ is defined to not exceed 0.3 . If $\theta \geq 0.2$ than the overall structural stiffness must be reviewed.

c) Design
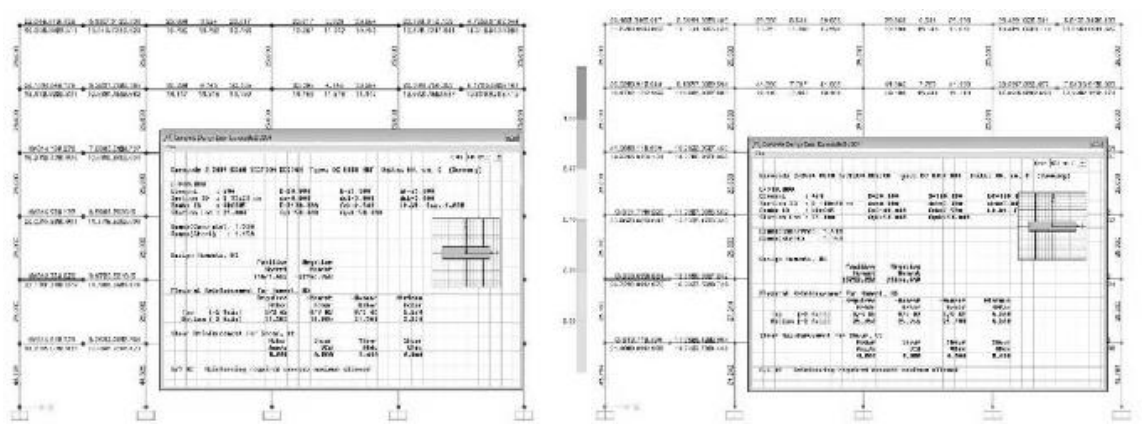

Fig. 14. Beam design: a) Edge frame R1; b) Interior frame R3.

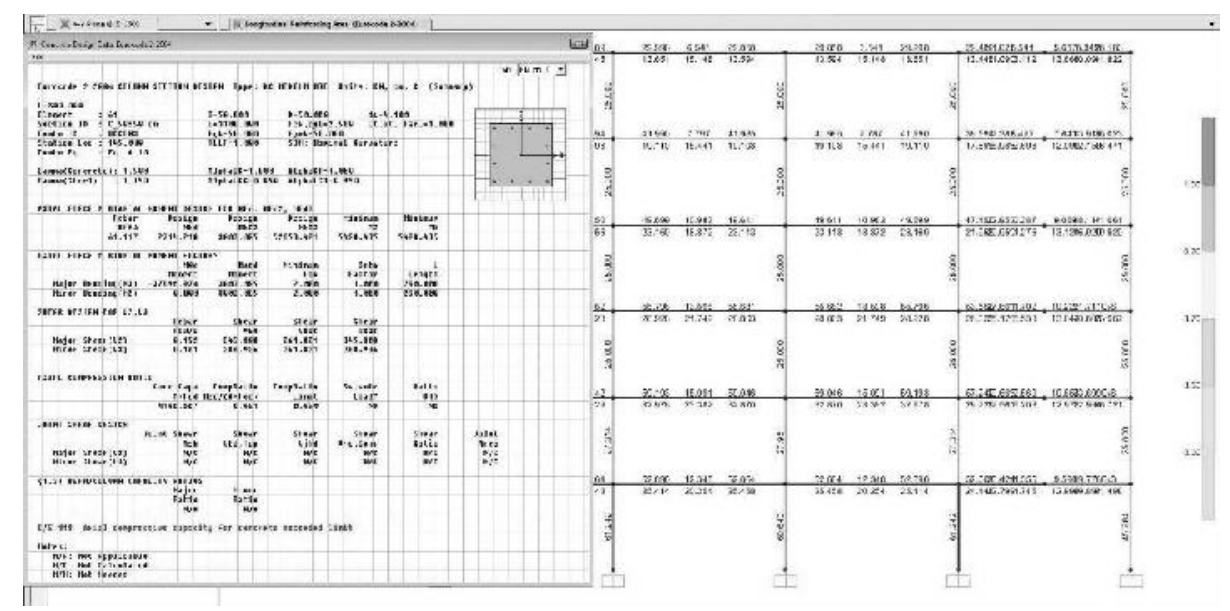

Fig. 15. Column design of interior frame R3.

From the analysis results presented in figures 14 and 15 can be concluded that the local ductility demands are not satisfied for this example. This structural system shows significant weakness as is nondissipative features during their seismic response. 


\section{Conclusions}

What is rational and optimal at these type of structures with flat slabs (without beams) is the fact that they provide a very simple design, great flexibility, clear floor space without beams, fast construction and time saving.

Critical regions at flat slab structures are the connections near the inner, peripheral and especially corner columns.

Punching shear failure check has to be done in the face of the column at critical perimeter, also at the outer perimeter where in this case the stress can be avoided from calculation.

Flat slab structures show more flexibility in comparison to the traditional structures with frames, and also they remain more vulnerable to the second order effects which have to be taken into account during the analysis of this type of structures.

Deformation/displacement control during seismic action, makes it necessary to combine flat slab system with stiffer systems such as shear walls.

\section{References}

1. Allen, FH., Darvall, P.: Lateral Load Equvalent Frame. ACI Journal, Proceedings, 74(7) 294299.

2. Dovich, LM., Wight, JK.: Effective slab width model for seismic analysis of at slab frames. ACI Structural Journal, 102(6) 868-875.

3. Dovich, LM., Wight, JK.: Lateral Response of Older Flat Slab Frames and Economic Effect on Retrofit Earthquake Spectra, V. 12, No. 4, 667-691.

4. Eurocode 8.: Design of structures for earthquake resistance - Part 1: General rules, seismic actions and rules for buildings (2004)

5. Grossman, JS.: Verication of proposed design methodologies for effective width of slabs in slabcolumn frames. ACI Structural Journal, 94(2) 181-196.

6. Hwang, S.J., Moehle, J.P.: Models for Laterally Loaded Slab-Column Frames. ACI Structural Journal, V. 97, No. 2, (2010) 345-353.

7. Megally, S., Ghali, A.: Punching Shear Design of Earthquake-Resistant Slab-Column Connections. ACI Structural Journal, V. 97-S73, 720-730.

8. Paulay, T., Priestley, M.J.N.: Seismic Design of Reinforced Concrete and Masonry Buildings. John Wiley \& Sons New York (1992).

9. Vanderbilt, M.D.: Equivalent frame analysis of unbraced reinforced con- crete buildings for static lateral loads. Structural Research Report No. 36. Civil Engineering Department, Colorado State University. Fort Collins Colorado (1981). 